\title{
An Integrated DEMATEL and AHP approach Multi Criteria Green Supplier Selection Process for Public Procurement
}

\author{
P. Etraj ${ }^{1}$, J. Jayaprakash ${ }^{2}$ \\ ${ }^{1}$ Research Scholar, Department of Mechanical Engineering, \\ Dr. MGR Educational and Research Institute University, Chennai, Tamil Nadu, India \\ nlpetraj@gmail.com \\ ${ }^{2}$ Professor, Department of Mechanical Engineering, \\ Dr. MGR Educational and Research Institute University, Chennai, Tamil Nadu, India
}

\begin{abstract}
Contemporary Supply Chain Management aims to maintain long-term partnership with the suppliers who are not only reliable, quality conscious, promptness of delivery, price competitive but also environmental conscious. The increasingly deterioration of environment in the fast phase forces many organizations particularly in the industrial sectors to develop and implement the Green Supply Chain Management (GSCM) in their business activity gains its momentum. In this research work an attempt has been made to integrate the Decision-Making Trial and Evaluation Laboratory (DEMATEL) and Analytic Hierarchy Process (AHP) for developing a unique Multi Criteria Decision Making (MCDM) model green supplier selection problem applicable to Government Public Procurement under typical Indian environment. Twenty six GSCM criteria under eight dimensions were identified from literature review and interview with six Decision Makers(DM), Sr.Managers from the Purchase Department, Materials Management Department, Production Department, Quality Control Department, Finance Department and Environmental Departments of the case study company, the Metropolitan Transport Corporation(MTC), a part of State owned Public Transport Corporation. By considering the interrelationships among the criteria, DEMATEL was applied to deal with the importance and causal relationships among the evaluation criteria of supplier selection. AHP has been applied to help the Decision Makers (DM) to make pair-wise comparison of suppliers who satisfy the GSCM criterion prioritized by the DEMATEL process. Obtained results show that the criteria of Green Supply Chain Management systems of Management Dimensions and Price Dimensions are the top two significant influences in selecting suppliers with Green Competencies. By identifying the structures and interrelationships, it can offer an insight for DMs to understand the cause-effort relationships and allow selecting suitable suppliers who have competence in GSCM and improve the environmental performance.
\end{abstract}

Keyword - Decision Making Trial and Evaluation Laboratory, Analytic Hierarchy Process, Multi Criteria Decision Making, Green Supply Chain Management.

\section{INTRODUCTION}

Green Supply Chain Management (GSCM) makes the organization to systematically evaluate the potential and appropriate business partners to maintain competitive advantage and increasingly aware of the propensity for environmental pollution incidents within their supply network to cost them in penalties, cleanup and consumer backlash [1]. Though a number of researchers have addressed the Green Supplier Selection Problems (GSSP) in Business to Business (B2B) and Business to Consumer (B2C) environments [2], but rarely explored it in public procurement for Government and Public Sector Undertakings [3]. The Indian PSUs are yet to recognize the GSSP as one of the critical factors in their business process that play key role on climate change. More recently, few Indian PSUs have attempted to develop a way to address the GSCM in electronics components production. This motivated the other PSUs[4] for developing comprehensive GSSP model to determine appropriate suppliers for their long-term collaborative business partnership. Most of the early literature are limited to exploring the broad environmental criteria for B2B and B2C and very little has been done in Government sector. Analytic Hierarchy Process (AHP) has been effectively used to evaluate the supplier's environmental performance, environmental costs, management competencies, green design, and environmental competencies in a GSSP for public procurement. It is also inevitable to include the economic, environmental, and social criteria into the GSSP model for public procurement [5]. The Decision Making Trial and Evaluation Laboratory (DEMATEL) approach has been considered as one of the best tools to deal with Cause and Effect Relationships (CER) among the evaluation criteria due to its ability to derive a direct graph showing the interrelationships among factors [6]. The main objective of this study is to develop an integrated model MCDM approach to select a green supplier in accordance with GSCM for Government Public Procurement in Indian scenario. 


\section{MATERIALS AND METHODS}

\section{A. Selection of DEMATEL Methodology}

Supplier Selection Problems in GSCM needs the Multi Criteria Decision Making (MCDM) approach and the related literature has proposed several supplier selection methodologies which require additional data for analysis the CER between criteria[7]. One of the such MCDM approach is Decision Making Trial and Evaluation Laboratory (DEMATEL) method, which uses matrices and diagrams for visualizing the structure of complicated causal relationships. Originally the DEMATEL was developed by the Science and Human Affairs Program of the Battelle Memorial Institute of Geneva between 1972 and 1976 and was used to solve the complicated and intertwined problem group [8,9,10,11]. DEMATEL technique does not need large amounts of data and is capable of revealing the relationship among these factors influencing other factors in the supplier selection [12]. DEMATEL modeling will better fits the problem examined in this study, and offers the advantage of providing a systematic approach to supplier selection in GSCM for Public Procurement[13].

\section{B. Selection of AHP Methodology}

The another popular MCDM tool, AHP has also been applied in conjunction with DEMATEL in the current research work. The AHP which was originally proposed by Saaty helps to reduce any multidimensional problem into one dimensional top down approach[14]. The application of AHP in current research work helps the decision makers to make pair-wise comparison between decision alternatives. The AHP can be applied to decompose any complicated problem into a one dimensional hierarchical structure of Goal, Criteria and Alternatives [15]. The pair-wise comparison has been carried out to assess the relative importance of variables to make the best decision among the alternatives [16]. Due to its flexibility in selecting the number of alternatives, AHP has been extensively used for SSP[17].

\section{Application of DEMATEL method.}

The DEMATEL method has been applied to the current research in eight steps as per the flow chart shown in Fig. 1, starting from formulating Direct Answer Matrix, Original Average Matrix, Normalizing the Direct Influence Matrix, Deriving the Total Relation Matrix and deciding threshold value to get the CER diagram [18].

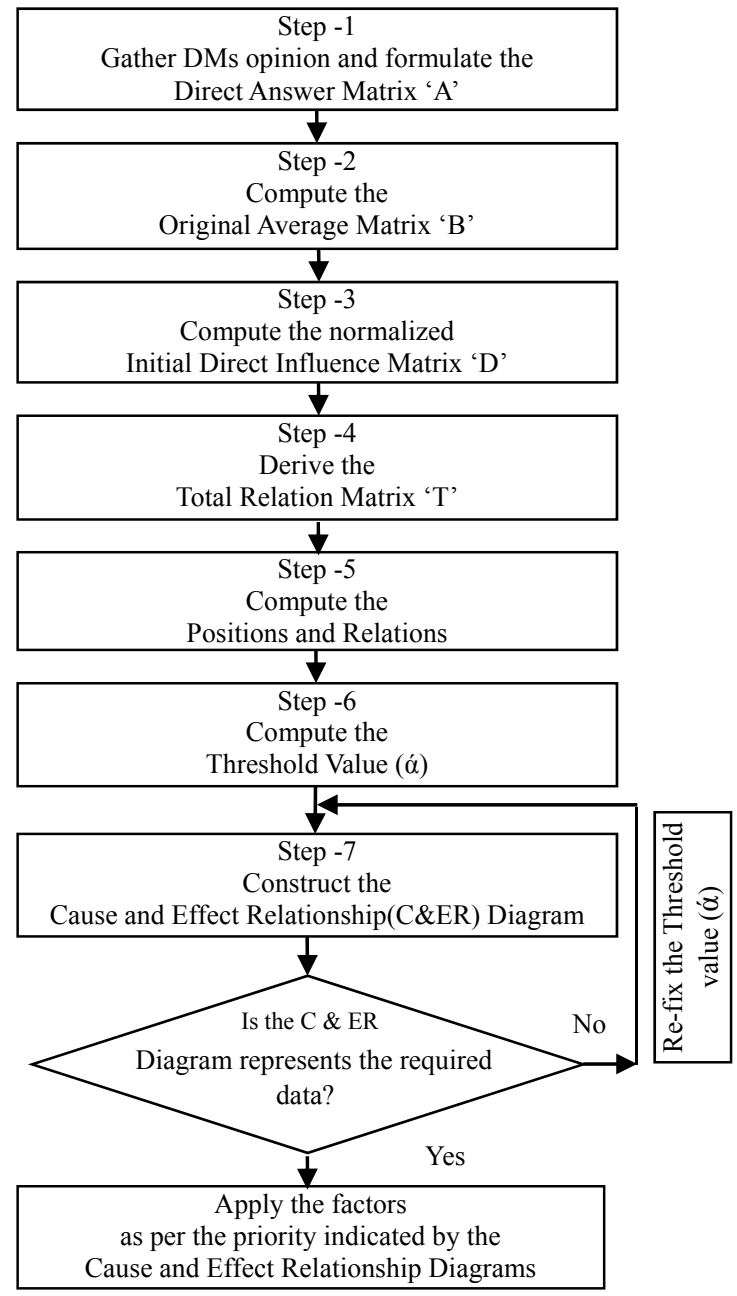

Fig. 1. DEMATEL Application Methodology 


\section{Step 1: Construct the Direct Answer Matrix;}

The Direct Answer Matrix for each dimensions are to be constructed by the scores awarded by ' $m$ ' Decision Makers (DM) with ' $n$ ' factors. Each DM is asked to view the degree of direct influence between two factors based on pair-wise comparison. The degree to which the DM perceived factor ' $i$ ' affects on factor " $j$ " is denoted by $\mathrm{a}_{\mathrm{ij}}^{\mathrm{k}}$. The integer score of ' 0 ' to ' 4 ' is assigned for each pairs as per the values given in Table I.

TABLE I

Degree of Influence and Numerical Score for Pair Wise Comparisons

\begin{tabular}{|clc|}
\hline Sl.No. & Degree of influence & Score \\
\hline 1 & No influence & 0 \\
2 & Low influence & 1 \\
3 & Medium influence & 2 \\
4 & High influence & 3 \\
5 & Very high influence & 4 \\
\hline
\end{tabular}

For each DM, ' $\mathrm{x}$ x n’ nonnegative Direct Answer Matrix is constructed as: $\mathrm{A}^{\mathrm{k}}=\left[\mathrm{a}^{\mathrm{k}}{ }_{\mathrm{ij}}\right]$,

with all diagonal elements are set to ' 0 ', where $\mathrm{k}$ is the number of the $\mathrm{DM}$ participating the evaluation process with $1 \leq \mathrm{k} \leq \mathrm{m}$, and hence $\mathrm{A}^{1}, \mathrm{~A}^{2}, \mathrm{~A}^{3}, \ldots \mathrm{A}^{\mathrm{m}}$ are the Direct Answer Matrix from ' $\mathrm{m}$ ' DMs.

\section{Step 2: Compute the Original Average Matrix;}

The ' $\mathrm{n}$ x n' Original Average Matrix, $\mathrm{B}=\left[\mathrm{b}_{\mathrm{ij}}\right]$, for all DMs opinions can be computed by averaging the scores of the ' $m$ ' DMs as shown below:

$$
b_{i j}=\frac{1}{m} \sum_{i=1}^{m} a^{k}{ }_{i j}
$$

Step 3. Compute the normalized Initial Direct Relation Matrix;

The normalized Initial Direct Relation Matrix D is obtained by normalizing the Original Average Matrix B in the following method:

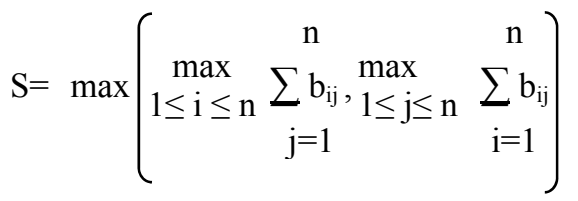

Thus $\mathrm{D}=\underline{\mathrm{B}}$

The positive scalar ' $s$ ' is equal to the bigger of two extreme sums. The matrix ' $D$ ' is obtained by dividing each element of ' $\mathrm{B}$ ' by the scalar and hence that each element ' $\mathrm{d}_{\mathrm{ij}}$ ' of matrix is ' $\mathrm{D}$ ' is between 0 and 1 .

\section{Step 4: Derive the Total Relation Matrix;}

Indirect effects between factors are measured by powers of ' $D$ '. A continuous decrease of the indirect effects of factors along the power of matrix ' $\mathrm{D}$ ', namely, $\mathrm{D}^{1}, \mathrm{D}^{2}, \mathrm{D}^{3}, \ldots \mathrm{D}^{\infty}$, guarantees convergent solutions to the matrix inversion similar to an absorbing Markov Chain Theory.

Note that

$$
\begin{aligned}
& \lim _{m \rightarrow \infty} D^{m}=[0]_{n \times n} \text { and } \\
& \lim _{m \rightarrow \infty}\left(1+D+D^{2}+D^{3}+\ldots \ldots \ldots D^{m}\right)=[1-D]^{-1}
\end{aligned}
$$

where ' 0 ' is the ' $\mathrm{n} x \mathrm{n}$ ' null matrix and ' $\mathrm{I}$ ' is the ' $\mathrm{n} \mathrm{x} n$ ' identity matrix. The total relation matrix ' $\mathrm{T}$ ' is an ' $\mathrm{n} x$ n' matrix and defined as follows.

$$
\begin{gathered}
\mathrm{T}=\left[\mathrm{t}_{\mathrm{ij}}\right] \sum_{\mathrm{i}=1}^{\infty} \mathrm{D}^{\mathrm{i}}=\mathrm{D}(1-\mathrm{D})^{-1} \quad \mathrm{i}, \mathrm{j}=1,2,3, \ldots \mathrm{n} \\
\quad \underset{\mathrm{k} \rightarrow \infty}{\operatorname{as} \lim ^{\mathrm{k}}=[0]_{\mathrm{n} \times \mathrm{n}}}
\end{gathered}
$$

where $\mathrm{D}=\left[\mathrm{d}_{\mathrm{ij}}\right]_{\mathrm{n} \times \mathrm{n}}, 0 \leq \mathrm{d}_{\mathrm{ij}} \leq 1$ and $0 \leq\left(\sum \mathrm{id}_{\mathrm{ij}}, \leq 1 \leq\left(\sum \mathrm{i} \mathrm{d}_{\mathrm{ij}}\right)<1\right.$ and at least one column sum $\leq\left(\sum \mathrm{i} \mathrm{d}_{\mathrm{ij}}\right.$ or one row sum 
$\leq\left(\sum \mathrm{jd}_{\mathrm{ij}}\right.$ equals to 1 .

Step 5: Compute the Positions and Relations;

The sum of rows and the sum of columns of the total relation matrix ' $\mathrm{T}$ ' are denoted as vector ' $\mathrm{r}$ ' and vector ' $c$ '. The calculation of ' $r$ ' and ' $c$ ' is given below.

$$
\begin{aligned}
& \mathrm{r}=\left[\mathrm{r}_{\mathrm{i}}\right]_{\mathrm{n} \times 1}=\left[\begin{array}{c}
\infty \\
\sum_{\mathrm{j}=1} \mathrm{t}_{\mathrm{ii}}
\end{array}\right]^{\mathrm{n} \times 1} \\
& \mathrm{c}=\left[\mathrm{r}_{\mathrm{j}}\right]_{1 \times \mathrm{n}}=\left(\begin{array}{c}
\infty \\
\sum_{\mathrm{i}=1} \mathrm{t}_{\mathrm{ij}}
\end{array}\right]^{\mathrm{t}} 1 \times \mathrm{n}
\end{aligned}
$$

Where superscript ' $t$ ' denotes transpositions.

- Let ' $r_{i}$ ' be the sum of the $i^{\text {th }}$ row in matrix ' $T$ '. The value ' $r_{i}$ ' shows the total effects, both direct and indirect exerted by the $\mathrm{i}^{\text {th }}$ factor on other factors.

- Let ' $c_{j}$ ' be the sum of the $j^{\text {th }}$ column matrix ' $T$ '. The value ' $c_{j}$ ' shows the total effects, both direct and indirect received by the $\mathrm{j}^{\text {th }}$ factor from other factors.

- The sum $\left(\mathrm{r}_{\mathrm{i}}+\mathrm{c}_{\mathrm{j}}\right)$ gives an index called the 'Position' representing the total effects both given and received by the $i^{\text {th }}$ factor, $i e,\left(r_{i}+c_{j}\right)$ shows the degree of importance that the $i^{\text {th }}$ factor plays in the system (total sum of effects given and received).

- The difference $\left(\mathrm{r}_{\mathrm{i}}-\mathrm{c}_{\mathrm{j}}\right)$ gives an index called the 'Relation' shows the net effect, the $\mathrm{i}^{\text {th }}$ factor contributes to the system.

- If $\left(\mathrm{r}_{\mathrm{i}}-\mathrm{c}_{\mathrm{j}}\right)$ is positive, then $\mathrm{i}^{\text {th }}$ factor is a 'net causer' and,

- If $\left(r_{i}-c_{j}\right)$ is negative, then $i^{\text {th }}$ factor is a 'net receiver'.

Step 6. Compute Threshold value(ó);

The threshold value ( $\dot{\alpha})$ can be computed by the average of the elements in total relation matrix ' $T$ '. Setting of threshold value will help to eliminate some of the minor effects elements of the total relation matrix ' $T$ ' $[18]$.

$$
\dot{\alpha}=\frac{\sum_{\mathrm{i}=1}^{\mathrm{n}} \sum_{\mathrm{j}=1}\left[\mathrm{t}_{\mathrm{ij}}\right]}{\mathrm{N}}
$$

Step 7. Construct Cause and Effect Relationship diagram;

The Cause and Effect Relationship diagram is constructed by mapping all coordinate sets of $\left(r_{i}+c_{j}, r_{i}-c_{j}\right)$ to visualize the complex interrelationship and provide information to judge which are the significant factors and their influence affect other factors [19]. Only the factors that ' $\mathrm{t}_{\mathrm{ij}}$ ' is greater than the threshold value ' $\alpha$ ' are selected and shown in cause and effect relationship diagram.

\section{Application of AHP method.}

The Principle of Decomposition, Principle of Comparative Judgment and Principle of Synthesis of Priorities are the three basic principles of AHP application. In this current research work AHP has been applied in nine steps as follows:-

Step 1: Set-up Hierarchy: The basic linear hierarchical structure shown in Fig. 2 is a top down approach consisting of Goal $\left(1^{\text {st }}\right.$ Level $)$, Criteria $\left(2^{\text {nd }}\right.$ Level $)$ and Alternatives $\left(3^{\text {rd }}\right.$ Level $)$. 


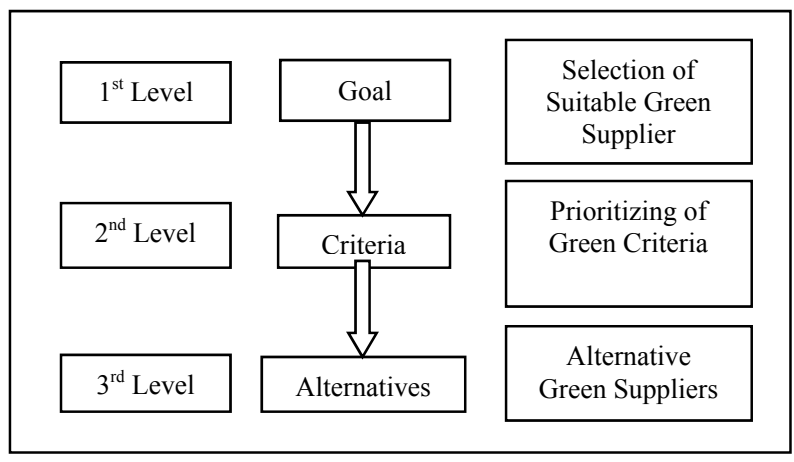

Fig. 2. Model Linear Hierarchy of "AHP"

The 'Goal' is to select a suitable Green Supplier for the case industry by pair-wise comparison with Factor/Criteria which are prioritized in the first stage by DEMATEL has been shown in Fig. 3.

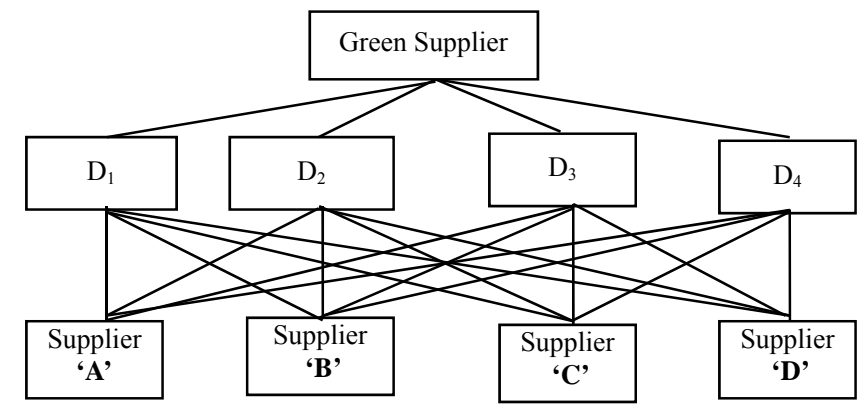

Fig. 3. The Proposed Hierarchy Structure of "AHP"

Step 2: Compare Criteria: The pair-wise comparison elements of one level with another level in their strength of influence are made by collecting the data through survey conducted in MTC. The pair wise comparisons are rated by nine point Saaty's scales [14] as given in Table II.

TABLE II

Saaty's Scale for Pair Wise Comparisons

\begin{tabular}{|lc|}
\hline \multicolumn{1}{|c|}{ Comparison Judgments } & Numerical value \\
\hline Equally preferred & 1 \\
Moderately preferred & 3 \\
Strongly preferred & 5 \\
Very strongly preferred & 7 \\
Extremely preferred & 9 \\
Intermediate values & $2,4,68$ \\
\hline Reciprocals for inverse comparisons \\
\hline
\end{tabular}

Let $\mathrm{C}_{1}, . ., \mathrm{C}_{\mathrm{n}}$ are elements of some level in a hierarchy and $\mathrm{w}_{1}, \ldots, \mathrm{w}_{\mathrm{n}}$, are weights of influence on some elements in the next level to be found. The elements of the matrix are selected representing judgment of pairwise comparisons. If " $\mathrm{a}_{\mathrm{ij}}$ " is the element of row " $\mathrm{i}$ " and column " $\mathrm{j}$ " of the matrix, then " $1 / \mathrm{a}_{\mathrm{ij}}$ " is the element of row " $\mathrm{j}$ " and column " $\mathrm{i}$ " of the matrix. ie " $\mathrm{aj}_{\mathrm{ji}}=1 / \mathrm{a}_{\mathrm{ij}}$ ". If the element " $\mathrm{a}_{\mathrm{ij}}$ " indicate the strength of " $\mathrm{C}_{1}$ " when compared with " $\mathrm{C}_{\mathrm{j}}$ ". This matrix is denoted by matrix " $\mathrm{A}$ ". When " $\mathrm{a}_{\mathrm{ji}}=1 / \mathrm{a}_{\mathrm{ij}}$ ", matrix " $\mathrm{A}$ " becomes reciprocal. If judgment is perfect in all comparisons, then " $a_{\mathrm{ik}}=\mathrm{a}_{\mathrm{ij} *} \mathrm{a}_{\mathrm{jk}}$ ", for all $\mathrm{i}, \mathrm{j}, \mathrm{k}$ and the matrix " $\mathrm{A}$ " becomes consistent. The matrix "A" has been shown as Fig. 4. 


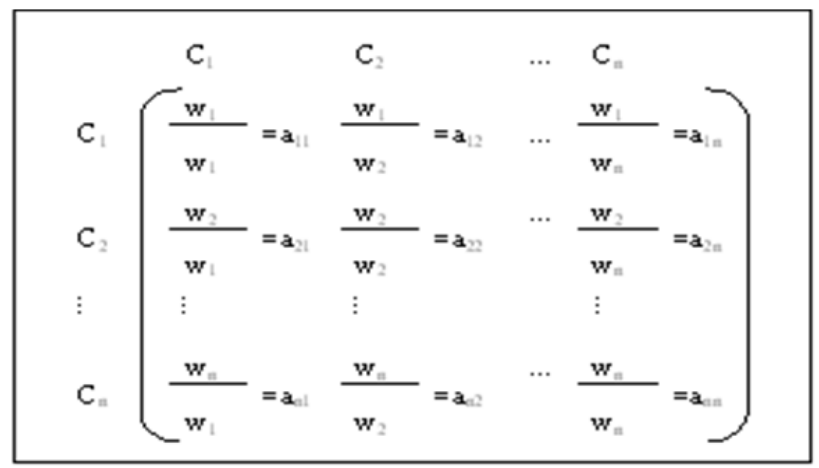

Fig. 4. Comparison Reciprocal Matrix

Step 3: Priority Vector for Criteria: The pair-wise comparison reciprocal matrix is obtained by:-

i. Sum the values in each column of the pair-wise comparison reciprocal matrix.

ii. Divide each value by the corresponding column sum to get the "Normalized Matrix".

iii. Average the values in each row of the normalized matrix and compute the "Priority Vector".

Step 4: Compare Alternatives: Repeat the step "i" to "iii" for each alternatives.

Step 5: Priority Vector for Alternatives: Compute the overall score for each decision alternatives.

Step 6: Overall Priority Vector: Rank the decision alternatives, according to the magnitude.

Step 7: Consistency Index: $\mathrm{CI}=\left(\lambda_{\max }-\mathrm{n}\right) /(\mathrm{n}-1)$, where, $\lambda_{\max }$ is the Principal Eigen value and " $\mathrm{n}$ " is the order of the matrix.

Step 8: Consistency Ratio: $\mathrm{CR}=\mathrm{CI} / \mathrm{RI}$, where $\mathrm{RI}$ is the Random Index as given in Table III.

TABLE III

Values for Random Index

\begin{tabular}{|c|c|c|c|c|c|c|c|c|c|c|}
\hline $\mathrm{n}$ & 1 & 2 & 3 & 4 & 5 & 6 & 7 & 8 & 9 & 10 \\
\hline $\mathrm{RI}$ & 0.00 & 0.00 & 0.58 & 0.90 & 1.12 & 1.24 & 1.32 & 1.41 & 1.45 & 1.49 \\
\hline
\end{tabular}

Step 9: Check for Consistency: If $0 \leq \mathrm{CR} \leq 0.1$, then the judgment is perfectly consistent and the criteria/alternative can be accepted and if $\mathrm{CR}>0.1$, the judgment is inconsistent and untrustworthy. Hence it needs to revise the subjective judgment.

\section{AN ILLUSTRATIVE CASE STUDY}

A case study has been conducted in bus body building facility of Metropolitan Transport Corporation (MTC), a wing of state owned Public Sector Transport Corporation, which provides urban mass transport service to the state capital city located in South India. The MTC has a six members (Decision Makers-DMs) Committee comprising of Sr.Managers from Purchase Department, Materials Management Department, Production Department, Quality Control Department, Finance Department and Environmental Departments [20]. Through a thorough and detailed study and analysis of the pertinent literature and in-depth interviews with the DMs, 26 criteria under 8 dimensions listed in Table IV, were recognized as the bases for GSCM for this research study [21]. The DMs were requested to fill out expert questionnaire using a five point scale as listed in the Table I, indicating the influence of each dimensions and criteria on other dimensions and criteria. In this section computation was divided into two parts for calculating on dimensions and criteria respectively [22, 23]. 
TABLE IV

GSCM Dimensions and Criteria

\begin{tabular}{|c|c|c|}
\hline GSCM Dimensions & Criteria & Code \\
\hline \multicolumn{2}{|l|}{ Price Dimensions } & $\mathbf{D}_{1}$ \\
\hline \multirow{3}{*}{$\begin{array}{l}\text { Suppliers ability to supply the products and services at optimum cost } \\
\text { and price }\end{array}$} & Price Competitiveness & $\mathrm{D}_{1} \mathrm{C}_{1}$ \\
\hline & Price Fluctuation & $\mathrm{D}_{1} \mathrm{C}_{2}$ \\
\hline & Payment Terms & $\mathrm{D}_{1} \mathrm{C}_{3}$ \\
\hline \multicolumn{2}{|l|}{ Quality Dimensions } & $D_{2}$ \\
\hline \multirow{4}{*}{ Suppliers capability to meet the buyers quality specifications. } & Compliance to Quality & $\mathrm{D}_{2} \mathrm{C}_{1}$ \\
\hline & Corrective and Preventive Action & $\mathrm{D}_{2} \mathrm{C}_{2}$ \\
\hline & Reliability of Quality & $\mathrm{D}_{2} \mathrm{C}_{3}$ \\
\hline & TQM Programme & $\mathrm{D}_{2} \mathrm{C}_{4}$ \\
\hline \multicolumn{2}{|l|}{ Delivery Dimensions } & $D_{3}$ \\
\hline \multirow{3}{*}{ Suppliers capability towards in-time delivery of products and services. } & Compliance to Delivery & $\mathrm{D}_{3} \mathrm{C}_{1}$ \\
\hline & Delivery Reliability & $\mathrm{D}_{3} \mathrm{C}_{2}$ \\
\hline & Geographical Location & $\mathrm{D}_{3} \mathrm{C}_{3}$ \\
\hline \multicolumn{2}{|l|}{ Environmental Dimensions } & $D_{4}$ \\
\hline \multirow{4}{*}{ Suppliers commitment to meet the environmental issues } & Environmental Compliance & $\mathrm{D}_{4} \mathrm{C}_{1}$ \\
\hline & Green Products and Design & $\mathrm{D}_{4} \mathrm{C}_{2}$ \\
\hline & Extended Producer Responsibility & $\mathrm{D}_{4} \mathrm{C}_{3}$ \\
\hline & \begin{tabular}{|l|} 
Corporate Environmental \\
Responsibility
\end{tabular} & $\mathrm{D}_{4} \mathrm{C}_{4}$ \\
\hline \multicolumn{2}{|l|}{ Public Procurement Policy Dimensions } & $\mathbf{D}_{5}$ \\
\hline \multirow{4}{*}{$\begin{array}{l}\text { Compliance to governmental laid down purchase procedures and to } \\
\text { follow guidelines. }\end{array}$} & KVIC Products & $\mathrm{D}_{5} \mathrm{C}_{1}$ \\
\hline & MSME/SSI Products & $\mathrm{D}_{5} \mathrm{C}_{2}$ \\
\hline & PSU/Government Sector Products & $\mathrm{D}_{5} \mathrm{C}_{3}$ \\
\hline & Corporate Social Responsibility & $\mathrm{D}_{5} \mathrm{C}_{4}$ \\
\hline \multicolumn{2}{|l|}{ Technical Dimensions } & $D_{6}$ \\
\hline \multirow{3}{*}{ Technical capacity established at suppliers organization } & Process Control Capability & $\mathrm{D}_{6} \mathrm{C}_{1}$ \\
\hline & Production Control Capability & $\mathrm{D}_{6} \mathrm{C}_{2}$ \\
\hline & ISO-QMS Compliance & $\mathrm{D}_{6} \mathrm{C}_{3}$ \\
\hline \multicolumn{2}{|l|}{ Financial Dimensions } & $D_{7}$ \\
\hline \multirow{2}{*}{ Financial implications related with the supplier } & Financial Capability & $\mathrm{D}_{7} \mathrm{C}_{1}$ \\
\hline & Financial Regulatory Compliance & $\mathrm{D}_{7} \mathrm{C}_{2}$ \\
\hline \multicolumn{2}{|l|}{ Managerial Dimensions } & $D_{8}$ \\
\hline \multirow{3}{*}{ Supplier's management control and caliber } & Organization Capability & $\mathrm{D}_{8} \mathrm{C}_{1}$ \\
\hline & Customer Focus & $\mathrm{D}_{8} \mathrm{C}_{2}$ \\
\hline & Purchase Order Reactiveness & $\mathrm{D}_{8} \mathrm{C}_{3}$ \\
\hline
\end{tabular}

\section{A. Applying DEMATEL on eight Dimensions}

Direct Answer Matrix are generated by pair-wise comparisons of 8 dimensions by using the relation $\quad A^{k}=$ $\left[\mathrm{a}^{\mathrm{k}}{ }_{\mathrm{ij}}\right]$ applying DEMATEL method. Original Average Matrix ' $\mathrm{B}$ ' has been computed by using the equation (2). Normalized Initial Direct Influence Matrix ' $D$ ' has been computed by using the equations (3) and (4). Total Relation Matrix ' $\mathrm{T}$ ' has been computed by using the equations (5) and presented as Table V.

TABLE V. Total Relation Matrix

\begin{tabular}{|lc|c|c|c|c|c|c|c|}
\hline & $\mathbf{D}_{\mathbf{1}}$ & $\mathbf{D}_{\mathbf{2}}$ & \multicolumn{1}{c}{$\mathbf{D}_{\mathbf{3}}$} & $\mathbf{D}_{\mathbf{4}}$ & $\mathbf{D}_{\mathbf{5}}$ & \multicolumn{1}{c|}{$\mathbf{D}_{\mathbf{6}}$} & $\mathbf{D}_{7}$ & $\mathbf{D}_{\mathbf{8}}$ \\
\hline $\mathbf{D}_{\mathbf{1}}$ & 1.18 & 1.72 & 1.56 & 1.63 & 1.64 & 1.72 & 1.73 & 1.71 \\
$\mathbf{D}_{\mathbf{2}}$ & 1.42 & 1.34 & 1.51 & 1.68 & 1.59 & 1.61 & 1.64 & 1.67 \\
$\mathbf{D}_{\mathbf{3}}$ & 0.89 & 1.31 & 1.17 & 1.45 & 1.32 & 1.24 & 1.32 & 1.29 \\
$\mathbf{D}_{\mathbf{4}}$ & 1.23 & 1.48 & 1.46 & 1.37 & 1.51 & 1.59 & 1.49 & 1.38 \\
$\mathbf{D}_{\mathbf{5}}$ & 1.24 & 1.35 & 1.34 & 1.37 & 1.29 & 1.54 & 1.44 & 1.34 \\
$\mathbf{D}_{\mathbf{6}}$ & 0.89 & 1.15 & 1.21 & 1.14 & 1.15 & 1.14 & 1.27 & 1.29 \\
$\mathbf{D}_{7}$ & 1.14 & 1.12 & 1.19 & 1.09 & 1.13 & 1.07 & 1.12 & 1.76 \\
$\mathbf{D}_{\mathbf{8}}$ & 0.97 & 0.98 & 1.11 & 1.05 & 1.21 & 1.05 & 1.03 & 1.26 \\
\hline
\end{tabular}


The threshold value ( $\alpha$ ) has been computed from the average of elements of Total Relation Matrix ' $T$ ' by using the equation (8) ie. (94.72/64=1.48). The values of ' $\mathrm{t}_{\mathrm{ij}}$ ' in Table IV, which are greater than $\alpha$ (1.48), are shown in box. Positions $\left(\mathrm{r}_{\mathrm{i}}+\mathrm{c}_{\mathrm{j}}\right)$ and Relations $\left(\mathrm{r}_{\mathrm{i}}-\mathrm{c}_{\mathrm{j}}\right)$ among dimensions are computed by using the equation (6) and (7). The direct and indirect effects of the criteria under 8 dimensions were summarized in Table VI.

TABLE VI. Positions and Relations among Dimensions

\begin{tabular}{|lccccc|}
\hline \multicolumn{1}{c}{ Dimensions } & Code & $\mathbf{r}_{\mathbf{i}}$ & $\mathbf{c}_{\mathbf{j}}$ & $\mathbf{r}_{\mathbf{i}}+\mathbf{c}_{\mathbf{j}}$ & $\mathbf{r}_{\mathbf{i}}-\mathbf{c}_{\mathbf{j}}$ \\
\hline Price Dimensions & $\mathrm{D}_{1}$ & 11.51 & 10.78 & 22.29 & 0.73 \\
Quality Dimensions & $\mathrm{D}_{2}$ & 12.46 & 10.56 & 23.02 & 1.90 \\
Delivery Dimensions & $\mathrm{D}_{3}$ & 12.89 & 8.96 & 21.85 & 3.93 \\
Environmental Dimensions & $\mathrm{D}_{4}$ & 11.03 & 10.84 & 21.87 & 0.19 \\
PP Policy Dimensions & $\mathrm{D}_{5}$ & 8.96 & 12.00 & 20.96 & -3.04 \\
Technical Dimensions & $\mathrm{D}_{6}$ & 9.62 & 11.04 & 20.66 & -1.42 \\
Financial Dimensions & $\mathrm{D}_{7}$ & 9.99 & 10.55 & 20.54 & -0.56 \\
Managerial Dimensions & $\mathrm{D}_{8}$ & 9.24 & 10.96 & 20.20 & -1.72 \\
\hline
\end{tabular}

The Cause and Effect Relationship among the eight dimensions are constructed and shown as Fig.5.

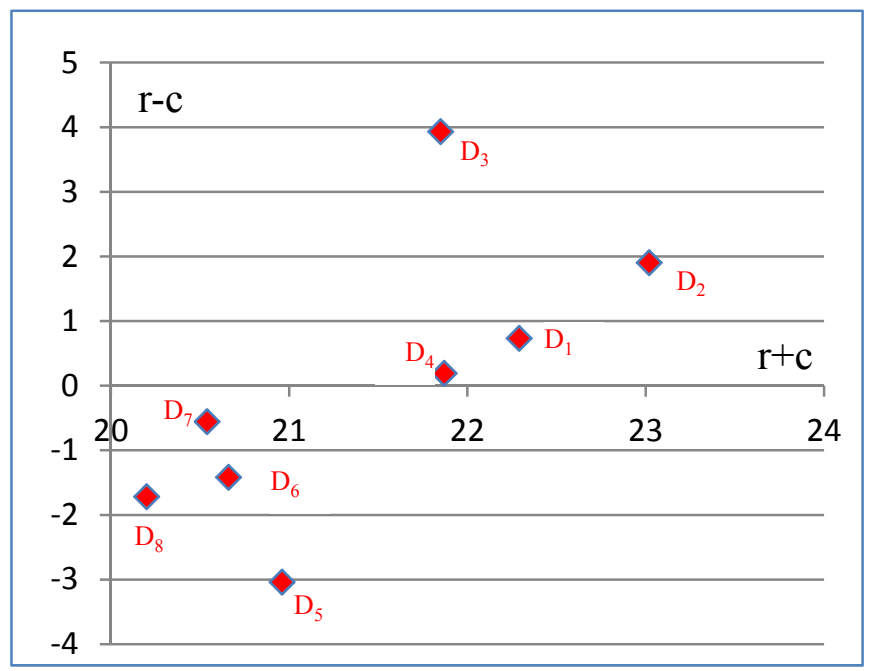

Fig. 5. The Cause and Effect Relationship Diagram

1). Positions and Relations: The 'Position' $(\mathrm{r}+\mathrm{c})$ values of the dimensional factors are presented in Table VI, shows that Quality Dimensions $\left(\mathrm{D}_{2}\right)$ is the most important factor with largest $(\mathrm{r}+\mathrm{c})$ value of 23.02 , whereas the Managerial Dimensions $\left(D_{8}\right)$ is the least important factor with the smallest $(\mathrm{r}+\mathrm{c})$ value of 20.20 . Considering the significance of Dimensions for GSCM as presented in Table VI, the importance of dimensions are identified as $\mathrm{D}_{2}>\mathrm{D}_{1}>\mathrm{D}_{4}>\mathrm{D}_{3}>\mathrm{D}_{5}>\mathrm{D}_{6}>\mathrm{D}_{7}>\mathrm{D}_{8}$. Based on (r-c) values, the eight dimensions are classified into:- (1) Cause Group Dimensions and (2) Effect Group Dimensions[24].

2). Cause Group-Dimensions: As per DEMATEL method, if the 'Relation' ( $\mathrm{r}-\mathrm{c}$ ) value is positive, such factors are classified as 'Net Causer' or 'Cause Group' and directly affect other factors. Also the degree of impact is proportionate to their numerical value. The highest (r-c) valued dimension has the greatest direct impact on other dimensions [25]. The outcome of the DEMATEL indicate that Price Dimensions $\left(\mathrm{D}_{1}\right)$, Quality Dimensions $\left(\mathrm{D}_{2}\right)$, Delivery Dimensions $\left(\mathrm{D}_{3}\right)$, and Environmental Dimensions $\left(\mathrm{D}_{4}\right)$ are fall into the Cause Group, since their (r-c) values are positive and their numeric values are $0.73,1.90,3.93$, and 0.19 respectively. This has been graphically depicted in Fig. 5.

3). Effect Group-Dimensions: On the other hand, if the 'Relation' ( $\mathrm{r}-\mathrm{c})$ value is negative, such factors are classified as 'Net Receiver' or 'Effect Group' and largely influenced by other factors. The present research shows that Public Procurement Policy Dimensions $\left(\mathrm{D}_{5}\right)$, Managerial Dimensions $\left(\mathrm{D}_{8}\right)$, Technical Dimensions $\left(D_{6}\right)$ and Financial Dimensions $\left(D_{7}\right)$ are falls into the Effect Group, since their $(r-c)$ values are negative and their numeric values are $-3.04,-1.72,-1.42$ and -0.56 respectively. 


\section{B. Applying AHP on Cause Group Dimensions}

The DMs are presented with the list of Cause Group Dimensions and their significance to the GSSP from DEMATEL application. The list of four suppliers namely 'Supplier 'A', Supplier 'B', Supplier 'C' and Supplier ' $\mathrm{D}$ ' identified from the case company's panel of suppliers also been provided to the DMs. The DMs are requested to apply the AHP among the four suppliers for each of the cause group dimensions and rate them by nine point Saaty's scales [14] as given in Table II.

1) Ranking of Dimensions: The global weight for the each of the Cause Group Dimensions with respect to the goal ie selecting Suitable Green Supplier are computed and depicted in Table VIII.

TABLE VIII. Pair-Wise Comparison Matrix of Criteria With Respect to Goal "Suitable Green Supplier"

\begin{tabular}{|c|c|c|c|c|c|c|c|c|c|c|c|c|}
\hline \multirow{2}{*}{ Criteria } & \multicolumn{4}{|c|}{ Pair-wise comparison matrix } & \multicolumn{4}{|c|}{ Normalized matrix } & \multirow{2}{*}{ Sum } & \multirow{2}{*}{$\begin{array}{l}\text { Priority } \\
\text { vector }\end{array}$} & \multirow{2}{*}{\multicolumn{2}{|c|}{$\begin{array}{l}\text { Check for } \\
\text { Consistency }\end{array}$}} \\
\hline & $D_{1}$ & $\mathrm{D}_{2}$ & $D_{3}$ & $D_{4}$ & $D_{1}$ & $D_{2}$ & $D_{3}$ & $D_{4}$ & & & & \\
\hline$\overline{D_{1}}$ & 1 & $1 / 2$ & 3 & 2 & 0.26 & 0.22 & 0.30 & 0.36 & 1.15 & 0.287 & $\lambda_{\max }=$ & 4.054 \\
\hline $\mathrm{D}_{2}$ & 2 & 1 & 4 & 2 & 0.52 & 0.44 & 0.40 & 0.36 & 1.73 & 0.432 & $\mathrm{n}=$ & 4 \\
\hline $\mathrm{D}_{3}$ & $1 / 3$ & $1 / 4$ & 1 & $1 / 2$ & 0.09 & 0.11 & 0.10 & 0.09 & 0.39 & 0.097 & $\mathrm{CI}=$ & 0.018 \\
\hline $\mathrm{D}_{4}$ & $1 / 2$ & $1 / 2$ & 2 & 1 & 0.13 & 0.22 & 0.20 & 0.18 & 0.73 & 0.184 & $\mathrm{CR}=$ & 0.020 \\
\hline Sum & 3.83 & 2.25 & 10.00 & 5.50 & 1.00 & 1.00 & 1.00 & 1.00 & 4.00 & 1.000 & & \\
\hline
\end{tabular}

1) Ranking of suppliers: The pair-wise comparisons of the suppliers with respect to the four cause group dimensions ie, Price Dimensions $\left(\mathrm{D}_{1}\right)$, Quality Dimensions $\left(\mathrm{D}_{2}\right)$, Delivery Dimensions $\left(\mathrm{D}_{3}\right)$, and Environmental Dimensions $\left(\mathrm{D}_{4}\right)$ are computed and presented as Tables IX, X, XI and XII.

TABLE IX. Pair-Wise Comparison Matrix of Suppliers With Respect to Criteria“" $D_{1}$-Price Dimensions"

\begin{tabular}{|c|c|c|c|c|c|c|c|c|c|c|c|c|}
\hline \multirow{2}{*}{$\begin{array}{l}D_{1} \text {-Price } \\
\text { Dimensions }\end{array}$} & \multicolumn{4}{|c|}{ Pair-wise comparison matrix } & \multicolumn{4}{|c|}{ Normalized matrix } & \multirow{2}{*}{ Sum } & \multirow{2}{*}{$\begin{array}{l}\text { Priority } \\
\text { vector }\end{array}$} & \multirow{2}{*}{\multicolumn{2}{|c|}{$\begin{array}{l}\text { Check for } \\
\text { Consistency }\end{array}$}} \\
\hline & $S$ 'A' & $S^{\prime} \cdot B^{\prime}$ & $S^{\prime} C^{\prime}$ & $S^{\prime} D^{\prime}$ & $S{ }^{\prime} A^{\prime}$ & $S$ ' $B$ ' & $S^{\prime} C^{\prime}$ & $S^{\prime} D^{\prime}$ & & & & \\
\hline Supplier 'A' & 1 & $1 / 2$ & 2 & 3 & 0.26 & 0.24 & 0.25 & 0.35 & 1.10 & 0.276 & $\lambda_{\max }=$ & 4.189 \\
\hline Supplier 'B' & 2 & 1 & 3 & 4 & 0.52 & 0.48 & 0.38 & 0.47 & 1.85 & 0.462 & $\mathrm{n}=$ & 4 \\
\hline Supplier 'C' & $1 / 2$ & $1 / 3$ & 1 & $1 / 2$ & 0.13 & 0.16 & 0.13 & 0.06 & 0.47 & 0.119 & $\mathrm{CI}=$ & 0.063 \\
\hline Supplier 'D' & $1 / 3$ & $1 / 4$ & 2 & 1 & 0.09 & 0.12 & 0.25 & 0.12 & 0.57 & 0.144 & $\mathrm{CR}=$ & 0.070 \\
\hline Sum & 3.83 & 2.08 & 8.00 & 8.50 & 1.00 & 1.00 & 1.00 & 1.00 & 4.00 & 1.000 & & \\
\hline
\end{tabular}

TABLE X. Pair-Wise Comparison Matrix of Suppliers With Respect to Criteria " $\mathrm{D}_{2}$-Quality Dimensions"

\begin{tabular}{|c|c|c|c|c|c|c|c|c|c|c|c|c|}
\hline \multirow{2}{*}{$\begin{array}{l}D_{2} \text {-Quality } \\
\text { Dimensions }\end{array}$} & \multicolumn{4}{|c|}{ Pair-wise comparison matrix } & \multicolumn{4}{|c|}{ Normalized matrix } & \multirow{2}{*}{ Sum } & \multirow{2}{*}{$\begin{array}{c}\text { Priority } \\
\text { vector }\end{array}$} & \multirow{2}{*}{\multicolumn{2}{|c|}{$\begin{array}{l}\text { Check for } \\
\text { Consistency }\end{array}$}} \\
\hline & $S$ 'A' & $S^{\prime} B^{\prime}$ & $S{ }^{\prime} C^{\prime}$ & $S$ ' $D$ ' & $S{ }^{\prime} A^{\prime}$ & $S^{\prime} B^{\prime}$ & $S{ }^{\prime} C^{\prime}$ & $S^{\prime} D^{\prime}$ & & & & \\
\hline Supplier 'A' & 1 & 2 & 3 & 2 & 0.43 & 0.52 & 0.46 & 0.25 & 1.66 & 0.415 & $\lambda_{\max }=$ & 4.186 \\
\hline Supplier 'B' & $1 / 2$ & 1 & 2 & 3 & 0.21 & 0.26 & 0.31 & 0.38 & 1.16 & 0.289 & $\mathrm{n}=$ & 4 \\
\hline Supplier 'C' & $1 / 3$ & $1 / 2$ & 1 & 2 & 0.14 & 0.13 & 0.15 & 0.25 & 0.68 & 0.169 & $\mathrm{CI}=$ & 0.062 \\
\hline Supplier 'D' & $1 / 2$ & $1 / 3$ & $1 / 2$ & 1 & 0.21 & 0.09 & 0.08 & 0.13 & 0.50 & 0.126 & $\mathrm{CR}=$ & 0.069 \\
\hline Sum & 2.33 & 3.83 & 6.50 & 8.00 & 1.00 & 1.00 & 1.00 & 1.00 & 4.00 & 1.000 & & \\
\hline
\end{tabular}

TABLE XI. Pair-Wise Comparison Matrix of Suppliers With Respect to Criteria " $\mathrm{D}_{3}$-Delivery Dimensions"

\begin{tabular}{|c|c|c|c|c|c|c|c|c|c|c|c|c|}
\hline \multirow{2}{*}{$\begin{array}{l}D_{3} \text {-Delivery } \\
\text { Dimensions }\end{array}$} & \multicolumn{4}{|c|}{ Pair-wise comparison matrix } & \multicolumn{4}{|c|}{ Normalized matrix } & \multirow{2}{*}{ Sum } & \multirow{2}{*}{$\begin{array}{c}\text { Priority } \\
\text { vector }\end{array}$} & \multirow{2}{*}{\multicolumn{2}{|c|}{$\begin{array}{l}\text { Check for } \\
\text { Consistency }\end{array}$}} \\
\hline & $S$ 'A' & $S^{\prime} \boldsymbol{B}$ ' & $S^{\prime} C^{\prime}$ ' & $S^{\prime} D^{\prime}$ & $S^{\prime} A^{\prime}$ & $S^{\prime} \boldsymbol{B}$ ' & $S^{\prime} C^{\prime}$ ' & $S^{\prime} D^{\prime}$ & & & & \\
\hline Supplier 'A' & 1 & 2 & $1 / 3$ & $1 / 4$ & 0.12 & 0.22 & 0.16 & 0.07 & 0.57 & 0.142 & $\lambda_{\max }=$ & 4.223 \\
\hline Supplier 'B' & $1 / 2$ & 1 & $1 / 4$ & $1 / 2$ & 0.06 & 0.11 & 0.12 & 0.13 & 0.42 & 0.106 & $\mathrm{n}=$ & 4 \\
\hline Supplier ' $C$ ' & 3 & 4 & 1 & 2 & 0.35 & 0.44 & 0.48 & 0.53 & 1.81 & 0.453 & $\mathrm{CI}=$ & 0.074 \\
\hline Supplier 'D' & 4 & 2 & $1 / 2$ & 1 & 0.47 & 0.22 & 0.24 & 0.27 & 1.20 & 0.300 & $\mathrm{CR}=$ & 0.082 \\
\hline Sum & 8.50 & 9.00 & 2.08 & 3.75 & 1.00 & 1.00 & 1.00 & 1.00 & 4.00 & 1.000 & & \\
\hline
\end{tabular}

TABLE XII. Pair-Wise Comparison Matrix of Suppliers With Respect to Criteria "D ${ }_{4}$-Environmental Dimensions"

\begin{tabular}{|c|c|c|c|c|c|c|c|c|c|c|c|c|}
\hline \multirow{2}{*}{$\begin{array}{l}\text { D }_{4} \text {-Environmental } \\
\text { Dimensions }\end{array}$} & \multicolumn{4}{|c|}{ Pair-wise comparison matrix } & \multicolumn{4}{|c|}{ Normalized matrix } & \multirow{2}{*}{ Sum } & \multirow{2}{*}{$\begin{array}{c}\text { Priority } \\
\text { vector }\end{array}$} & \multirow{2}{*}{\multicolumn{2}{|c|}{$\begin{array}{l}\text { Check for } \\
\text { Consistency }\end{array}$}} \\
\hline & $S$ ' $A$ ' & $S$ ' $B$ ' & $S$ ' $C$ ' & $S \cdot D$ ' & $S$ 'A' & $S$ ' $B$ ' & $S$ ' $C$ ' & $S$ ' $D$ ' & & & & \\
\hline Supplier 'A' & 1 & 2 & $1 / 2$ & $1 / 3$ & 0.15 & 0.29 & 0.10 & 0.15 & 0.69 & 0.173 & $\lambda_{\max }=$ & 4.254 \\
\hline Supplier 'B' & $1 / 2$ & 1 & $1 / 2$ & $1 / 2$ & 0.08 & 0.14 & 0.10 & 0.23 & 0.55 & 0.138 & $\mathrm{n}=$ & 4 \\
\hline Supplier 'C' & 2 & 2 & 1 & $1 / 3$ & 0.31 & 0.29 & 0.20 & 0.15 & 0.95 & 0.237 & $\mathrm{CI}=$ & 0.085 \\
\hline Supplier 'D' & 3 & 2 & 3 & 1 & 0.46 & 0.29 & 0.60 & 0.46 & 1.81 & 0.452 & $\mathrm{CR}=$ & 0.094 \\
\hline Sum & 6.50 & 7.00 & 5.00 & 2.17 & 1.00 & 1.00 & 1.00 & 1.00 & 4.00 & 1.000 & & \\
\hline
\end{tabular}


2) Overall ranking of suppliers: The priority vectors of the Criteria (Dimensions) and Alternatives (Suppliers) are computed. The ranking of the four suppliers ie. "Supplier 'A', Supplier 'B', Supplier ' $\mathrm{C}$ ' and Supplier ' $\mathrm{D}$ ' in order of the magnitude of their overall score are listed in Table XIII.

TABLE XIII. Overall priority vector and Supplier Ranking

\begin{tabular}{|lccccccc|}
\hline Alternatives & $\mathbf{D}_{\mathbf{1}}$ & $\mathbf{D}_{\mathbf{2}}$ & $\mathbf{D}_{\mathbf{3}}$ & $\mathbf{D}_{\mathbf{4}}$ & Criteria & Priority & Final Ranking \\
\hline Supplier 'A' & 0.276 & 0.415 & 0.142 & 0.173 & 0.287 & 0.304 & I \\
Supplier 'B' & 0.462 & 0.289 & 0.106 & 0.138 & 0.432 & 0.293 & II \\
Supplier 'C' & 0.119 & 0.169 & 0.453 & 0.237 & 0.097 & 0.195 & IV \\
Supplier 'D' & 0.144 & 0.126 & 0.300 & 0.452 & 0.184 & 0.208 & III \\
\hline
\end{tabular}

\section{RESULTS AND ANALYSIS}

The Cause and Effect Relationship Diagram of DEMATEL for the dimensions and the Priority Vector of AHP for the criteria are analyzed and presented in the following paragraphs.

1) Prioritizing of Dimensions by DEMATEL: The analysis of Cause and Effect Relationship Diagram (Fig.-5) of DEMATEL show that the Quality Dimension $\left(\mathrm{D}_{2}\right)$ is the highest priority dimension for the selection of Green Suppliers to the case company with the position $(\mathrm{r}+\mathrm{c})$ value of "23.02" followed by Price Dimension $\left(D_{1}\right)$ with the position value of "22.29", Environmental Dimension $\left(\mathrm{D}_{4}\right)$ with the position value of " 21.87 " and Delivery Dimension $\left(\mathrm{D}_{3}\right)$ with the position value of " 21.85 " respectively [26].

2) Prioritizing of Dimensional Criteria by AHP: The analysis of priority vectors depicted in Table VII resulting from the application of AHP show that for the case study industry, the Quality Dimensional criteria $\left(\mathrm{D}_{2}\right)$ found to be the most important attribute with a score of $43.20 \%$, followed by Price Dimensional criteria $\left(\mathrm{D}_{1}\right)$ as the second priority with a score of $28.70 \%$, and the Environmental Dimensional criteria $\left(\mathrm{D}_{4}\right)$ falls to the third priority with a score of $18.40 \%$ and the Delivery Dimensional criteria $\left(\mathrm{D}_{3}\right)$ having a marginal score of $9.70 \%$ as the least important criterion. The comparative analysis of the priority of dimensions by DEMATEL and AHP has been depicted in Fig. 6.

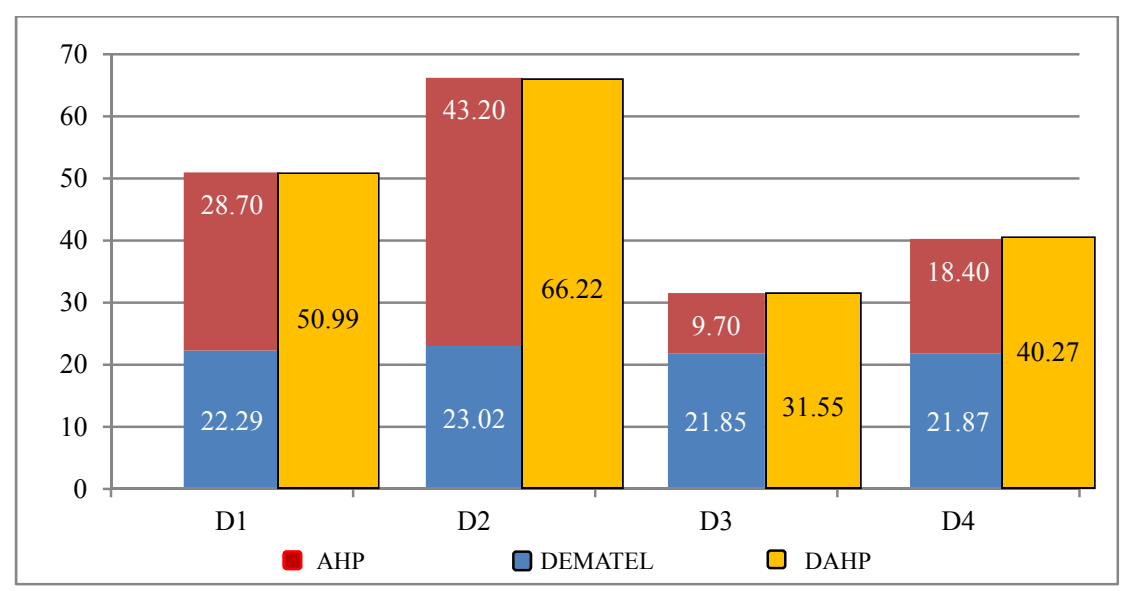

Fig. 6, Prioritizing of Dimensional Criteria by Integrated DEMATEL and AHP.

1) Prioritizing of Dimensional Criteria by integrating DEMATEL and AHP: The summary of supplier's overall score in order of preference show that the Supplier-'A', is best suitable green supplier for MTC as it got the highest overall rank with a score of 30.40\% followed by Supplier-'B', with a score of $29.30 \%$. The Supplier-'D' and Supplier-'C' got $20.80 \%$ and $19.50 \%$ respectively.

\section{CONCLUSIONS}

This paper presents a hybrid model of MCDM approach by integrating DEMATEL and AHP for selecting suitable Green Suppliers for the Case Company. The current research work is based on the set of factors and key criterion that are selected from the existing resource bank and also from earlier research articles. The uniqueness of the current study stems from the fact that the Environmental Factors are consider as the crucial leading factors for the GSSP. There is an increasing interest on implementing efficient GSCM techniques in Government departments as well in PSUs too. The authors applied 26 criteria under eight dimensions of Green Supplier Selection strategies in this research work. The proposed framework brings several metrics to green supplier 
evaluation and selection. A model framework with 26 criteria has not been proposed in literature yet. The results also show that 18 out of 26 criteria are falls into the 'Cause Group' and the remaining 8 criteria are of "Effect Group". This is one of the most critical information to the case industry 'MTC' to select highly influential GSCM criteria for its business operations. Though the DEMATEL, AHP and the integrated DAHP methods are yielding to the identical results, the integrated approach converged into more precisely distinguished the goals. This helps the Decision Makers (DM) from pitfall of selecting wrong suppliers which follows very close to the best one with marginal difference.

The advantage of the current method stems by its inbuilt flexibility by applying to dissimilar dimensions with varied conditions. This feature is also unique with regard to previous studies. Any Government Departments or PSUs under typical Indian environment who propose to incorporate environmental criteria into their supplier selection and evaluation process can adopt the present model as a road map for their future business operations.

\section{REFERENCES}

[1] Ho, W., Xu, X., Dey, P.K., Multi-Criteria Decision Making approaches for supplier evaluation and selection: a literature review. Eur. J. Oper. Res. 202, pp 16-24, 2010.

[2] Kaoutar BENNIS and Lahcen BAHI, Hybird Fuzzy Decision Making Framework for Environmental Impact Assessment, Tangier, Morocco, International Journal of Engineering and Technology, Vol. 7, No. 1, Feb-Mar 2015.

[3] Gupta.R.K. and Pravin Chandra, Integrated Supply Chain Management in The Government Environment, International Conference - OPSCON'98 On "Supply Chain Management For Global Competitiveness", Novemeber 20-21, 1998 At Management Development Institute, Gurgaon.

[4] Handfield, R., Walton, S., Sroufe, R., Melnyk, S., Applying environmental criteria to supplier assessment: a study in the application of the Analytical Hierarchy Process. European Journal of Operation Research, 141, pp 70-87, 2002.

[5] Etraj,P. and Jayaprakash.J., AHP to select Environmentally Conscious Supplier for SSCM: A Case Study, Applied Mechanics and Materials, Vol.813-814, pp 1133-1139, 2015.

[6] Chang, B., Chang, C.W., Wu, C.H., Fuzzy DEMATEL method for developing Supplier Selection Criteria. Expert Syst. Appl. 38, pp 1850-1858, 2011.

[7] Raman Singh, Harish Kumar and R.K. Singla, TOPSIS Based Multi-Criteria Decision Making of Feature Selection Techniques for Network Traffic Dataset, International Journal of Engineering and Technology, Vol. 5, No. 6, Dec 2013-Jan 2014.

[8] Gabus, A. and Fontela, E.,World Problems, an Invitation to Further Thought within the Framework of DEMATEL. Batelle Geneva Research Center, Geneva, 1972.

[9] Gabus A. and Fontela, E., Perceptions of the world problematique: communication procedure, communicating with those bearing collective responsibility (DEMATEL Report No. 1). Battelle Geneva Research Centre, Geneva, 1973.

[10] Fontela, E. and Gabus, A., DEMATEL innovative methods, Technical report no. 2, Structural analysis of the world problematique. Battelle Geneva Research Institute, 1973.

[11] Fontela, E. and Gabus, A., DEMATEL, Innovative Methods, Report No. 2 Structural Analysis of the World Problematique. Battelle Geneva Research Institute, 1974.

[12] Maghsud Amiri, Jamshid Salehi Sadaghiyani, Nafiseh Payani, and Mahdi Shafieezadeh, Developing a DEMATEL method to prioritize distribution centers in supply chain, Management Science Letters 1, pp 279-288, 2011.

[13] Chia-Wei Hsua, Tsai-Chi Kuob, Sheng-Hung Chenc, Allen H. Hud, Using DEMATEL to develop a carbon management model of supplier selection in Green Supply Chain Management, Journal of Cleaner Production, Vol.56, pp 164 -172, 2013.

[14] R.Narasimhan, S.Talluri and S.K.Mahapatra, Multiproduct, Multicriteria model for supplier selection with product life-cycle considerations, Decision Sciences, vol. 37, pp 577-603, 2006.

[15] Saaty, Thomas L. Relative Measurement and its Generalization in Decision Making: The Analytic Hierarchy/Network Process. RACSAM (Review of the Royal Spanish Academy of Sciences, Series A, Mathematics), 2008.

[16] M.M.Ravikumar, K. Marimuthu and H. Abdul Zubar, Application of AHP for Lean Implementation Analysis in 6 MSMEs, International Journal of Engineering and Technology, Vol. 6, No. 2, Apr-May 2014.

[17] Devendra Singh Verma and Ajitabh Pateriya, Supplier Selection through AHP: A Case Study In Small Scale Manufacturing Organization, IJ of Engineering Trends and Technology, Volume 4, Issue 5, pp 1428-1433, 2013.

[18] David Asamoah, Jonathan Annan and Samuel Nyarko, AHP approach for Supplier Evaluation and Selection in a Pharmaceutical Manufacturing Firm in Ghana, IJ of Business and Management, Vol.7, pp 49-62, 2012.

[19] Detcharat Sumrit and Pongpun Anuntavoranich, Using DEMATEL Method to Analyze the Causal Relations on Technological Innovation Capability Evaluation Factors in Thai Technology-Based Firms, International Transaction Journal of Engineering, Management \& Applied Sciences \& Technologies, Volume 4, No.2, pp 81-103, 2013.

[20] Li, C. W., and Tzeng, G. H., Identification of a threshold value for the DEMATEL method using the maximum mean de-entropy algorithm to find critical services provided by a semiconductor intellectual property mall. Expert Systems with Applications, 36, pp 9891-9898, 2009.

[21] K.Arun Vasantha Geethan, Dr.S.Jose and C.Sunil Chandar, Methodology for Performance Evaluation of Reverse Supply Chain, International Journal of Engineering and Technology, Vol.3 (3), 213-224, Jun-July 2011.

[22] Chang, B., Chang. C-W. and Wu, C-H., Fuzzy DEMATEL method for developing supplier selection criteria. Expert System Application 38, pp $1850-1858,2011$

[23] Tzeng, G.H., Chiang, C.H. and Li, C.W. Evaluating intertwined effects in e-learning programs: a novel hybrid MCDM model based on factor analysis and DEMATEL. Expert Systems with Applications, 32 (4), pp1028-1044, 2007.

[24] K.Govindan, Multi Criteria Decision Making approaches for green supplier evaluation and selection: A Literature Review, Journal of Cleaner Production, XXX, pp 1-18, 2013.

[25] R.Narasimhan, S.Talluri and S.K.Mahapatra, Multiproduct, Multicriteria model for supplier selection with product life-cycle considerations, Decision Sciences, vol. 37, pp 577-603, 2006 
[26] S.Kumar, S.Teichman and T.Timpernagel, A Green Supply Chain is a requirement for profitability, International Journal of Production Research, 50(5), pp 1278-1296, 2012.

\section{AUTHOR PROFILE}

P.Etraj : He has obtained his M.E., (Manufacturing) from Madras Institute of Technology, Anna University Chennai. He has 28 years of industrial experience working in Indian Railways, in various departments like Production Control, Training and Development, Quality System and Material Planning. He is currently pursuing his Ph.D. research in Green Supply Chain Management, at Dr. MGR Educational and Research Institute University, Chennai, Tamil Nadu, India. E.Mail.nlpetraj@gmail.com

Prof. Dr.J.Jayaprakash M.E., Ph.D.,: He is currently working as a Professor, Department of Mechanical Engineering, Dr. MGR Educational and Research Institute University, Chennai, Tamil Nadu, India. Formerly he was Professor \& Head, Department of Mechanical Engineering, Loyola Institute Technology, Chennai. He has 17 years of teaching experience. His specialization includes Production Engineering, Mechanical Engineering and Industrial Engineering. 